\title{
Preparation and Characterization of Tungsten Carbide WC/Cobalt Composites by Powder Metallurgy Method
}

\author{
D.V.Satya Prasad Nulu, M.N.V. Alekhya, P.Phani Prasanthi, K. Manoj Kumar, G E V Ratna \\ Kumar
}

\begin{abstract}
The Tungsten carbide (WC) based composites are good choice to replace the traditional conventional materials for obtaining high hardness and wear resistance. This work investigates the influence of cobalt content on the characterization of Tungsten carbide. The composite specimens are prepared by using powder metallurgy technique. The effect of cobalt material on the performance of Tungsten carbide hardness, fracture toughness is estimated by conducting suitable experiments. While performing experiments, a powder mixture of $89 \%$ WC, $11 \%$ of Co was manufactured with powder metallurgy, under appropriate milling conditions and Sintering temperature to ensure uniform microstructure. From the present work the optimum sintering temperature of Tungsten carbide mixed nano cobalt composite is identified. The crystalanity of the resulting materials is identified from a rapid analytical technique, $X$-ray Diffraction.
\end{abstract}

Keywords : Tungsten carbide, cobalt, powder metallurgy, hardness, Fracture toughness, sintering temperature

\section{INTRODUCTION}

Tungsten carbide is a multipurpose material due to its mechanical properties. These materials used in many applications such as ball point balls, bearings, nozzles, jewellery, cutting and drilling tools. There is always a scope to enhance the already available Tungsten carbide in the view of mechanical, electrical properties, cost and weight etc.With this aim, many researchers carried a research work on Tungsten carbide by adding different materials. Rengui He et al. [1] used sol-gel process to manufacture tungsten carbide with nano-cobalt coatings found that the

Revised Manuscript Received on December 30, 2019.

* Correspondence Author

D.V.Satya Prasad Nulu, Assistant Professor, Department of Mechanical Engineering, Eluru College of Engineering, Eluru, Andhra Pradesh, India.

M.N.V. Alekhya, Assistant Professor, Department of Mechanical Engineering, Sir C.R Reddy College of Engineering, Eluru, Andhra Pradesh, India

P.Phani Prasanthi*, Associate Professor, Department of Mechanica Engineering, Prasad V. Potluri Siddhartha Institute of Technology, Kanuru, Andhra Pradesh, India.

K. Manoj Kumar, Assistant Professor, Department of Mechanical Engineering, Eluru College of Engineering, Eluru, Andhra Pradesh, India.

G E V Ratna Kumar, Assistant Professor, Department of Mechanical Engineering, Eluru College of Engineering, Eluru, Andhra Pradesh, India.

(C) The Authors. Published by Blue Eyes Intelligence Engineering and Sciences Publication (BEIESP). This is an open access article under the CC BY-NC-ND license (http://creativecommons.org/licenses/by-nc-nd/4.0/) coating of nano cobalt nano powder on the tungsten carbide improved the transverse strength.

The better bonding behaviour of tungsten carbide and cobalt particles was observed by GuoShengda et al. [2].

Using Vickers and Brinell (spherical) micro indenters, the elastic and plastic properties of Ge-Se binary and Ge-Sb-Se ternary chalcogenide glasses are identified [3]. The hardness and indentation load have an inversely proportional relation. These parameters are studied by Eswar Prasad and Ramesh [4] and identified the relation between the silicon crystals size and hardness. These finding are different for elastic modulus and this property is independent on the indentation.

Another case study is focused on flash sintering. Using this technique, the tungsten carbide and iron matrix composite is studied by changing the weight percentage of titanium carbide [5]. While designing a cutting tool, most importance will be given to the wear parameter. Carbide based tools are commonly used tools for cutting tool and these materials are investigated by infusing the cobalt content in the carbide to check the wear behaviour [6].

Considerable work has been performed on Nickel based alloys by using additives such as chromium carbides [7].

The performance or application of newly designed material can be obtained by their mechanical properties with the support of Microstructure. Using Thermodynamics and diffusion kinetics modelling tools, the above mentioned behaviour is explored [8].

Along with wear properties, the friction behaviour are also plays an important role. The friction, wear behaviour of cementite carbide is identified using ball on disk contrast test [9]. The high damage rate of titanium alloys machining rate is explored [10].

In the present work, the hardness and fracture toughness response with sintering temperature is explored using experimental and analytical studies.

\section{EXPERIMENTATON AND METHODOLOGY}

The Tungsten carbide and nano cobalt mixed composite specimens are prepared by using powder metallurgy technique. The composition of WC and nano cobalt is maintained at $89 \%$ and $11 \%$ respectively. Initially, the metal powders are collected according to their weight fraction and these powders are mixed in V-cone blender. After mixing of composite ingredients, compaction process has done by preparing a suitable mould.

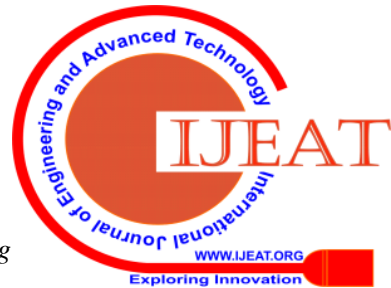




\section{Preparation and Characterization of Tungsten Carbide WC/Cobalt Composites by Powder Metallurgy Method}

The prepared powder is transferred into the mould and die is pressed for compaction using a hydraulic press with the capacity of 10 tonne at a rated pressure of 100 bar. The specimens after compaction is presented in Fig.1

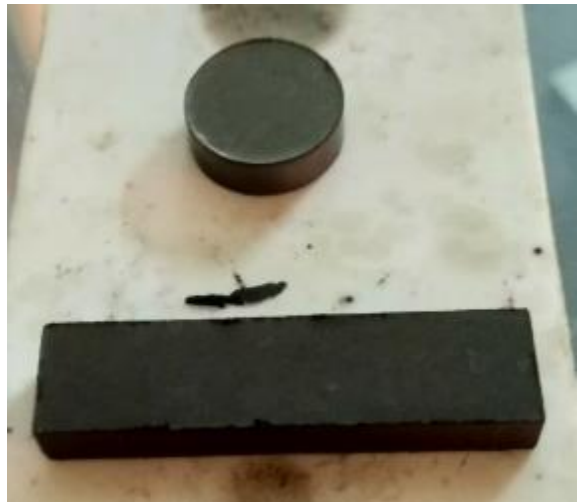

Fig.1. Testing Specimens after compaction

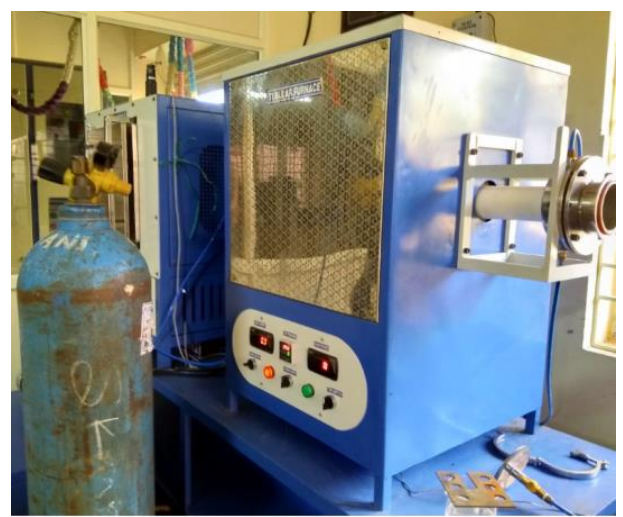

Fig.2. Tubular Furnace for sintering

The next operation followed to prepare a composite material is sintering. The specimens at this stage are sintered at different temperature of $1000-1800^{\circ} \mathrm{C}$ with an interval of $100^{\circ} \mathrm{c}$ for four hours in tubular microwave furnace.

This is very important stage to acquire the desired properties for prepared composite. Later the specimens are removed from the furnace and cooled in the atmosphere temperature. The Micro structure report of composite material is presented in Fig.3. The contribution of each phase in composite material is conformed to with microstructure report produced in Microscope of V.R Siddhartha Engineering College, Vijayawada, Andhra Pradesh, India. The pixels/ $\mu m$, calib: MS100X, Unit: $\mu \mathrm{m}, \mathrm{X}: 1.6233, \mathrm{Y}: 1.615$.

The area considered for the analysis is 0.1163 sqmm. The standards used are ASTME 562. The information obtained from the Microstructure is in terms of Volume fraction Fig.2., shows the Microstructure along with the volume fraction of each material in the component (Bar graph) primary material about $69 \%$ cobalt is $32 \%$ and the remaining percentage is shared other elements.

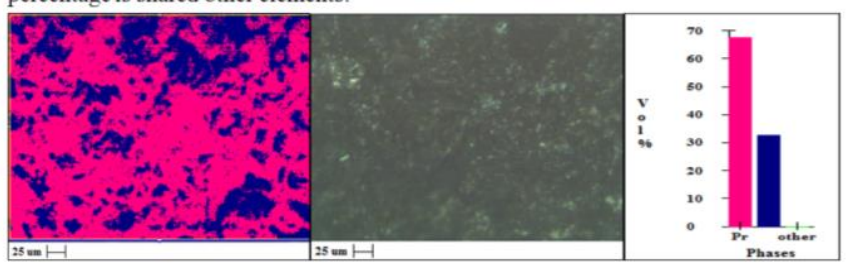

Fig.3. Microstructure Image of Tungsten carbide and cobalt composit

\section{RESULTS AND DISCUSSIONS}

In this section, the influence of sintering temperature on the hardness of the Tungsten carbide combined with the cobalt nano powder is provided. The sintering temperature decides the final properties of the composite materials. In this study, the sintering temperature is varied from $1000^{\circ}$ to $1800^{\circ} \mathrm{C}$ in tubular microwave sintering.

And these temperature influences on the hardness of the Tungsten carbide mixed nano cobalt composite is identified. In terms of hardness, the optimum sintering temperature is identified. Using Brinell hardness testing machine with diamond indenter and the range of load applied on the prepared specimen is $500 \mathrm{~kg}$ to $3000 \mathrm{~kg}$.

The variation of hardness with respect to the sintering temperature is identified and the same thing is represented in Fig.3. and up to the temperature of $1400^{\circ} \mathrm{c}$, the hardness of the Tungsten carbide with cobalt powder is increasing and later decrement in the hardness is observed.

The material prepared by power metallurgy is checked for XRD to know the crystal structure of the material.

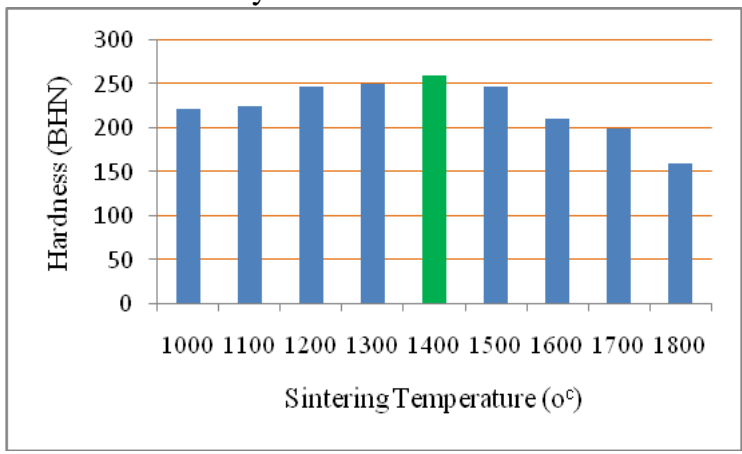

Fig.3. Hardness with sintering temperature

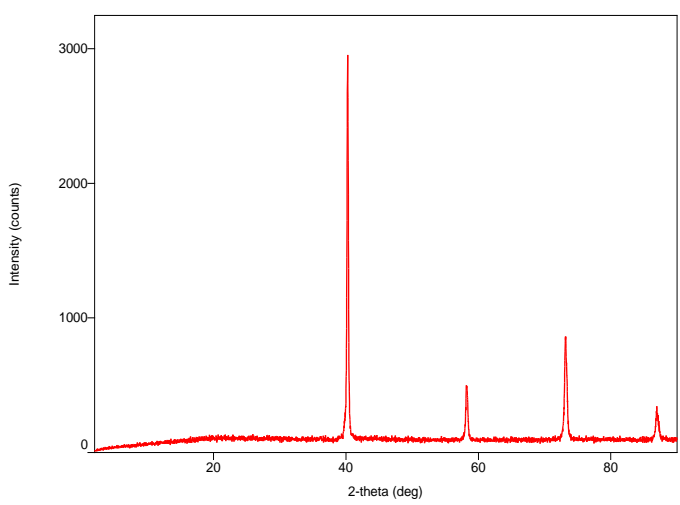

Fig. 4 XRD of tested specimen

Phase identification, crystal structure, and lattice parameter of the crystal solids are identified with X-ray diffraction (XRD) technique. The information obtained from the XRD is used to find the Bragg's law $(\theta)$.

To perform the XRD analysis, fine powder samples are used and these powders are placed on the sample holder. The incident light beam rays fall on the sample, will be scattered by the sample atoms. From the scatter rays, the maximum intensity and the corresponding angle will be identified.

The reflecting planes where the X-rays are scattered will be identified and these atomic planes are termed as reflecting planes.

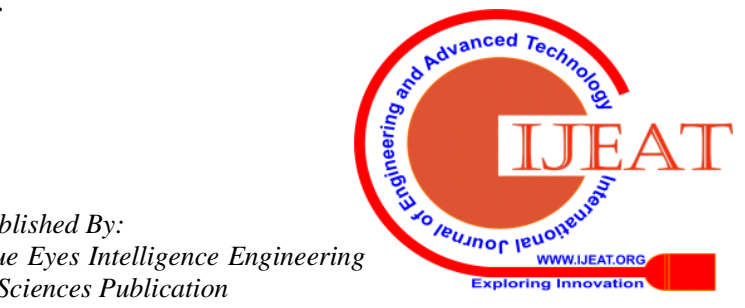


The Bragg's law gives the relation between the wavelengths $(\alpha)$ of the X-rays, the atomic plane spacing (d) and the reflection angle $(\theta)$ and the law is $2 d \sin \theta=n \lambda$. Using this information the XRD peaks would be identified.

Table.1. XRD Results of tungsten carbide combined with nano cobalt

\begin{tabular}{|l|l|l|l|l|}
\hline S,No. & $\begin{array}{l}\text { 2-theta } \\
\text { (deg) }\end{array}$ & d (ang.) & $\begin{array}{l}\text { Height } \\
\text { (counts) }\end{array}$ & $\begin{array}{l}\text { FWHM } \\
\text { (deg) }\end{array}$ \\
\hline 1 & $40.222(5)$ & $2.2403(3)$ & $2211(47)$ & $0.194(4)$ \\
\hline 2 & $58.182(10)$ & $1.5843(2)$ & $342(19)$ & $0.262(11)$ \\
\hline 3 & $73.141(7)$ & $1.29285(10)$ & $654(26)$ & $0.292(8)$ \\
\hline 4 & $86.938(16)$ & $1.11968(17)$ & $187(14)$ & $0.33(2)$ \\
\hline
\end{tabular}

Table.2. XRD parameters of tungsten carbide combined with nano cobalt

\begin{tabular}{|l|l|l|l|}
\hline S.No. & $\begin{array}{l}\text { Int. I } \\
\text { (counts } \\
\text { deg) }\end{array}$ & $\begin{array}{l}\text { Int. W } \\
\text { (deg) }\end{array}$ & $\begin{array}{l}\text { Asym. } \\
\text { Factor }\end{array}$ \\
\hline 1 & $595(4)$ & $0.269(8)$ & $0.95(10)$ \\
\hline 2 & $124.5(19)$ & $0.36(3)$ & $0.69(12)$ \\
\hline 3 & $266(3)$ & $0.41(2)$ & $1.05(10)$ \\
\hline 4 & $87(2)$ & $0.47(5)$ & $1.1(3)$ \\
\hline
\end{tabular}

After characterizing the crystal structure from XRD analysis, using the analytical equations, the fracture toughness of the Tungsten carbide combined with nano cobalt is calculated from hardness of the composite.

The brinell hardness number is converted into Vickers hardness number using the conversion equation and using the following equation 1 , the fracture toughness is identified.

$$
\mathrm{K}_{\mathrm{IC}}=0.16 \mathrm{x}(\mathrm{c} / \mathrm{a})^{-1.5} \mathrm{x} \sqrt{\mathrm{HV}}
$$

\section{Eq.1}

Where $\mathrm{HV}$ is the Vickers hardness value obtained by converting Brinell number to Vickers hardness, $\mathrm{P}$ is the applied loads, $\mathrm{d}$ is the Mean length of the diagonals of the Indentation.

The fracture toughness is high at $1400^{\circ} \mathrm{c}$. [11]. Fracture toughness of the composite is increasing with the sintering temperature of $1400^{\circ} \mathrm{C}$. Later the magnitude is decreased (Fig.5).

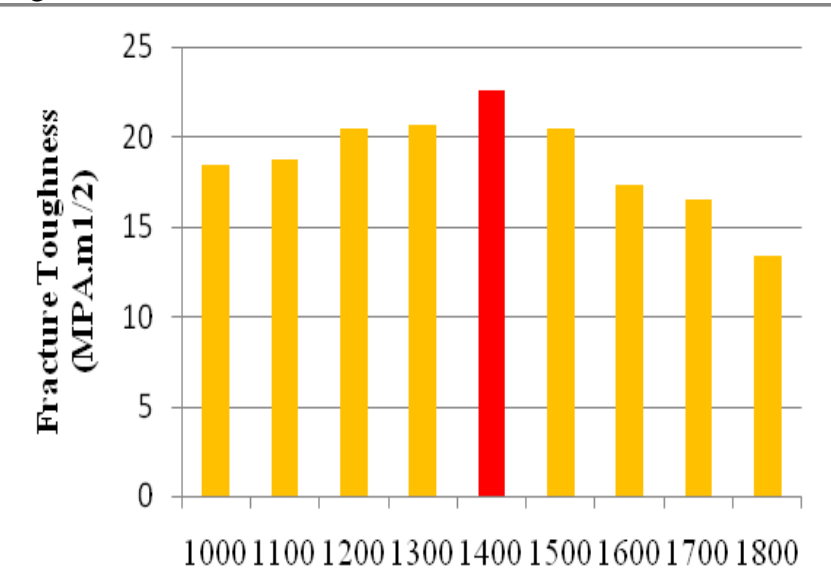

Sintering Temperature $\left(0^{c}\right)$

\section{CONCLUSION}

Tungsten carbide can use as a cutting tool because of its excellent mechanical properties such as hardness and fracture toughness, but due to its less toughness it may reduce the tool life. Cobalt is added to impact the strength and toughness of Tungsten carbide, and the mechanical properties are improved.

While designing cutting tools from these materials through power metallurgy technique, appropriate sintering temperature is very important parameter because the sintering temperature decides the final Microstructure. The higher the sintering temperature, the higher the hardness level of a material, as sintering temperature increase, the grain growth increased as well. The hardness of the matrix is about 280 HBN which was tested in brinell hardness test. So this ceramic composite matrix (WC-Co) can be used as a cutting tool. The optimum sintering temperature of the composite is $1400^{\circ} \mathrm{C}$ for considered composite material

\section{REFERENCES}

1. RenguiHe, Jianying Wang, MengHe, HailinYang, Jianming Ruan, "Synthesis of WC composite powder with nano-cobalt coatings and its application in WC-4Co cemented carbide", Ceramics Internationa Volume 44, Issue 9, 15 June 2018, Pages 10961-10967. https://doi.org/10.1016/j.ceramint.2018.03.174

2. GuoShengda, ShenTao, BaoRui, Yang Jiangao, YiJianhong, "Synthesis and Characterization of WC-6Co Nanocrystalline Composite Powder", Rare Metal Materials and Engineering, Volume 47, Issue 7, July 2018, Pages 1986-1992. https://doi.org/10.1016/S1875-5372(18)30169-3

3. ArunK.Varshneya, Daniel J.Mauro, "Microhardness, indentation toughness, elasticity, plasticity, and brittleness of $\mathrm{Ge}-\mathrm{Sb}-\mathrm{Se}$ chalcogenide glasses", Journal of Non-Crystalline Solids, Volume 353, Issues 13-15, 15 May 2007, Pages 1291-1297

4. K.Eswar Prasad, K.T.Ramesh, "Hardness and mechanical anisotropy of hexagonal SiC single crystal polytypes", Journal of Alloys and Compounds, Volume 770, 5 January 2019, Pages 158-165.

5. Siqi Xiang, ShaofeiRen, Yihan Liang, Xinfang Zhang, "Fabrication of titanium carbide-reinforced iron matrix composites using electropulsing-assisted flash sintering”, Materials Science and Engineering: AVolume 768, 19 December 2019, 138459.

6. M.Chandrashekar, K.V.Sreenivasa Prasad, "The Effect of Cobalt on Wear behavior of Cemented Carbide cutting tools for machining of Titanium alloy", Materials Today: Proceedings Volume 5, Issue 2, Part 2, 2018, Pages 7678-7684

7. PatriceBerthod, LydiaToubal, "Dependence of titanium carbide stability at elevated temperatures on Co content in $\mathrm{Co}(\mathrm{Ni})-25 \mathrm{Cr}-1.6 \mathrm{Ti}-0.4 \mathrm{C}$ superalloys", Materials Chemistry and Physics, Volume 212, 15 June 2018, Pages 260-267

8. Armin Salmasi, aAndreasBlomqvist, Henrik Larsson, "Geometry effects during sintering of graded cemented carbides: Modelling of microstructural evolution and mechanical properties", Results in Materials, Volume 1, August 2019, 100008.

9. YunsongLian, Chenliang $\mathrm{Mu}$, Lei Wang, Bin Yao, JianxinDeng Shuting Lei, "Numerical simulation and experimental investigation on friction and wear behaviour of micro-textured cemented carbide in dry sliding against TC4 titanium alloy balls", International Journal of Refractory Metals and Hard Materials, Volume 73, June 2018, Pages 121-131.

10. Xiuxu Zhao, WeiKe, Shuanshuan Zhang, WenhanZheng, "Potential failure cause analysis of tungsten carbide end mills for titanium alloy machining”, Engineering Failure Analysis, Volume 66, August 2016, Pages 321-327.

11. Evans A. G. and Charles E. A. (1976). Fracture Toughness Determination by Indentation, J. Am. Ceram. Soc., Vol. 59, (1976), pp. 371-372.

Fig.5. Fracture toughness with sintering temperature 
Preparation and Characterization of Tungsten Carbide WC/Cobalt Composites by Powder Metallurgy Method

\section{AUTHORS PROFILE}

D.V.Satya Prasad Nulu, Assistant Professor, Department of Mechanical Engineering, Eluru College of Engineering, Eluru, Andhra Pradesh, India

M.N.V. Alekhya, ${ }^{2}$ Assistant Professor, Department of Mechanical Engineering, Sir C.R Reddy College of Engineering, Eluru, Andhra Pradesh, India

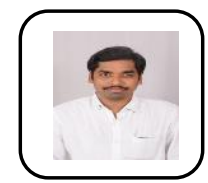

K. Manoj Kumar, Assistant Professor, Department of Mechanical Engineering, Eluru College of Engineering, Eluru, Andhra Pradesh, India

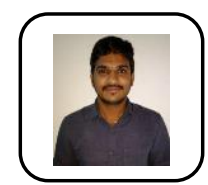

G E V Ratna Kumar, Assistant Professor, Department of Mechanical Engineering, Eluru College of Engineering, Eluru, Andhra Pradesh, India 